\title{
Assessing the additive and dominance genetic effects of vegetative propagation ability in Eucalyptus-influence of modeling on genetic gain
}

\author{
Garel Makouanzi • Jean-Marc Bouvet • Marie Denis • \\ Aubain Saya • François Mankessi • Philippe Vigneron
}

Received: 29 January 2014 / Revised: 19 May 2014 / Accepted: 28 May 2014 / Published online: 1 July 2014

(C) Springer-Verlag Berlin Heidelberg 2014

\begin{abstract}
To study the genetic determinism of propagation by cutting, 2,115 individuals of 83 full-sib families of the Eucalyptus urophylla $\times$ Eucalyptus grandis hybrid were used as stock plants and propagated by cuttings. Shoot production (PROD) and cutting success (CUT) were measured in two periods corresponding to the dry and rainy seasons. The experiments showed a significant effect of propagation period, suggesting the combined influence of environmental conditions and physiological state of stock plants. Using the linear mixed model (LMM) and the generalized one (GLMM) to take into account the non-normal distribution, the additive and dominance variances were estimated. They were significantly different from zero for PROD and CUT, as was the interaction between genetic effects and periods. The dominance variance was equal or higher than additive variance for both traits (1 $\left.<\sigma^{2}{ }_{D} / \sigma^{2}{ }_{A}<1.5\right)$. Broad- and narrow-sense heritabilities change with the model type. For PROD, with LMM, they were moderate $\left(h^{2}{ }_{\text {ss }}=0.182\right.$ and $\left.H_{\text {sl }}^{2}=0.443\right)$ but high with GLMM $\left(h^{2}{ }_{\mathrm{ss}}=0.431\right.$ and $\left.H_{\mathrm{sl}}^{2}=0.891\right)$. For CUT, the same
\end{abstract}

Communicated by J. Beaulieu

G. Makouanzi $\cdot$ A. Saya $\cdot$ P. Vigneron

Centre de Recherche sur la Durabilité et la Productivité des

Plantations Industrielles, CRDPI, BP: 1291, Pointe-Noire, Congo

J.-M. Bouvet $\cdot$ M. Denis $\cdot$ P. Vigneron

CIRAD, Research unit AGAP "Genetic improvement and adaptation of Mediterranean and tropical plants", TA A-108/01,

34398 Montpellier Cedex 5, France

F. Mankessi

University of Marien Ngouabi 1654, Rue Motaba, PRONAR,

Plateaux des 15ans, BP: 1315, Brazzaville, République du Congo

J.-M. Bouvet $(\bowtie)$

CIRAD, TA A-108/01, 34398 Montpellier Cedex 5, France

e-mail: jean-marc.bouvet@cirad.fr trend was observed for variances but the genetic control was weaker with heritabilities smaller than 0.3 . The selection accuracy $(r)$ was affected by the statistical model, $r=0.94$ and $r=0.42$ for PROD using LMM and GLMM, respectively. Genetic correlations between PROD, CUT, and the field growth of clones at 25 months were relatively low. These results are important elements to consider for breeding strategies that target genetic gain for both field growth and cutting success.

Keywords Propagation by cutting - Linear mixed model . Generalized linear mixed model · Variance components . Heritability $\cdot$ Correlations

\section{Introduction}

Vegetative propagation is widely used for large-scale Eucalyptus industrial plantations as it allows full capture of the additive, dominance, and epistasis effects underlying the traits of interest and deployment of the desired genotypes. The increase in genetic gain when the improvement program produces clone varieties is well known in the Eucalyptus genus (Zobel 1993; Barbour and Butcher 1995; MacRae and Cotterill 1997; Hossain et al. 2004). This is a common strategy for deployment of tropical or sub-tropical Eucalyptus species such as Eucalyptus urophylla, Eucalyptus grandis, Eucalyptus camaldulensis, and their hybrids such as the widely used E. urophylla $\times E$. grandis. The yearly production of several hundred million cuttings by the Eucalyptus forest industry to supply its planting programs calls for considerable investments in terms of manpower, nurseries, watering, and fertilization. In addition, the cost of the upstream breeding and selection programs providing the selected genotypes to be propagated considerably increases the final cost of the plantlets. So, one of the challenges of clonal forestry is the 
suitability of the species for vegetative propagation (Kovacevic et al. 2008), which represents a fundamental selection criterion of clonal varieties. Vegetative propagation-related traits, i.e., stock plant production and survival, cutting survival during rooting phase, duration of rooting phase, and final rooting rate, are the major traits to consider for selection and then condition the feasibility and cost of varietal deployment. Practitioners are well aware of between-species variability in vegetative propagation traits, even if it is poorly reported in the literature. Huge clone-toclone variation in cutting success is experienced daily in nurseries (Martin and Quillet 1974; Mankessi et al. 2010) and limits the number of genotypes used on an industrial scale. Genetic control of vegetative propagation traits has been studied for a few industrial species such as Eucalyptus globulus (Borralho and Wilson 1994; Lemos et al. 1997), Eucalyptus nitens (Tibbits et al. 1997), and Eucalyptus sideroxylon (Burger 1987). Knowledge of the genetic to phenotypic variance ratio is of major importance in predicting future genetic gain and choosing optimum strategies for breeding and selection. Moderate to large estimates of narrow- and broad-sense heritability are needed for accurate selection of parents to be crossed and clones to be deployed on an industrial scale.

Capacity for vegetative propagation is simultaneously conditioned by the physiological age of plant donors (Davis 1988; Hackett 1988; Pierik 1990; Browne et al. 1997; Mankessi et al. 2009), by genetic predisposition to vegetative propagation (Rauter 1983; Radosta 1989; Radosta et al. 1994), and by environmental factors (Zsuffa 1968; Farmer et al. 1989; Radosta 1989; Kovacevic et al. 2004, 2005). Influential factors affecting rooting ability can be divided into exogenous and endogenous, and are liable to interact. The season (i.e., combined effect of temperature, moisture, light availability...) is considered as the most influential exogenous factor affecting rooting ability (Rauter 1983; Monteuuis et al. 1995; Teklehaimanot et al. 2004; Danthu et al. 2008). Endogenous factors include genetic identity (Shepherd et al. 2005) and the physiological state of plant (Mankessi et al. 2009).

Although vegetative propagation by cuttings of E. urophylla $\times E$. grandis is well documented (Martin and Quillet 1974; Chaperon and Quillet 1977; Saya et al. 2008), the magnitude of additive and non-additive genetic variation and the heritability of vegetative propagation ability are poorly understood in Eucalyptus. Furthermore, the genetic and environmental relationships between rooting ability and other growth and adaptive traits are poorly documented in Eucalyptus compared with other perennial angiosperms (Foster 1985; Paul et al. 1993; Radosta et al. 1994; Goldfarb et al. 1998; Foster et al. 2000; Baltunis et al. 2007). However, a better understanding of these correlations is crucial for a breeding strategy which deploys clones as varieties.
With the aim of improving our knowledge of the genetic and environmental determinants of propagation ability by cutting in Eucalyptus, a large experiment was undertaken using a full-sib progeny test of E. urophylla $\times E$. grandis. Based on the 83 elite full-sib families of E. urophylla $\times E$. grandis, this study was undertaken to (i) assess the genetic control of propagation ability in the framework of intensively managed container-ground stock plants, (ii) assess the level of additive and non-additive genetic effects on shoot production and cutting success, and (iii) determine the correlation between the vegetative propagation traits and initial growth in the field. Data analysis was the subject of a special focus because the categorical variables used in this study, often used in genetic trials, need to be carefully studied when variance components and genetic parameters are crucial information. We therefore investigated the performance of the generalized linear mixed model (GLMM) and compared it with that of the classic mixed model (LMM).

\section{Material and methods}

\section{Material and methodology applied}

A 13 (female) $\times 11$ (male) E. urophylla $\times$ E. grandis incomplete factorial mating design (Table 1) was used in order to produce 83 full-sib families by controlled pollination. One to 36 (i.e., nearly 25 on average) young healthy and vigorous seedlings per family, according to availability, were transplanted, generating 2,115 stock plants grown on a mixture of a black sandy soil and charcoal (volume proportion 4:1) substrate with $100 \mathrm{~g}$ of ammonium nitrate. Each container contained $4 \mathrm{dm} 3$ of substrate. Twelve plants of the same fullsib families were planted in each container. Up to a maximum of three containers per full-sib families were randomly distributed in the nursery area dedicated to the experiment.

Stock plants were managed according to Saya et al. (2008) in order to stimulate the production of numerous actively growing axillary shoots with short internodes. After reaching 5-7 cm long, the stock plants produced shoots displaying chlorophyllian leaves and apex, in accordance with Saya et al. (2008). Approximately 7 to 8 days after their decapitation, the young plantlets started sprouting. The first cuttings started to be produced by the 24th day after decapitation. Cuttings were harvested every 7 days. Harvesting was spread out over 1 year with discontinuous periods, divided into three. A preliminary period (day 30 to day 74 ) was a stock plant formation phase, during which preliminary observations were made and the collected cuttings were not transplanted. Thus, cutting success was not measured for this period. A 1st propagation period (day 120 to day 155 corresponding to JulyAugust), was considered in this analysis. A 2nd propagation period (day 335 to day 356 corresponding to February- 
Table 1 Pedigree and number of stock plants (full-sib individuals) for each crossing. The "9-101" code used for the male corresponds to E.grandis (9) and to the parent identity (101). The "14-109" code of the female corresponds to E.urophylla (14) and to the parent identity (109)

\begin{tabular}{|c|c|c|c|c|c|c|c|c|c|c|c|c|c|}
\hline & & \multicolumn{11}{|c|}{ Male (Eucalyptus grandis) } & \multirow[t]{2}{*}{ Total } \\
\hline & & $9-101$ & $9-111$ & $9-113$ & $9-115$ & $9-118$ & $9-131$ & $9-15$ & $9-159$ & $9-21$ & $9-29$ & $9-66$ & \\
\hline \multirow{14}{*}{$\begin{array}{l}\text { Female } \\
\qquad \text { (Eucalyptus urophylla) }\end{array}$} & $14-109$ & & 35 & 4 & 35 & 7 & & 36 & 34 & 35 & 36 & 34 & 256 \\
\hline & $14-142$ & & 6 & 31 & 34 & 4 & & 34 & & 33 & 21 & 34 & 197 \\
\hline & $14-144$ & 9 & 32 & 4 & 32 & 24 & 25 & 8 & 28 & 31 & 36 & 35 & 264 \\
\hline & $14-230$ & & 30 & & 34 & & & 31 & 10 & 36 & 24 & 35 & 200 \\
\hline & $14-233$ & & & & 22 & & & & 2 & 18 & & & 42 \\
\hline & $14-242$ & & 33 & 7 & 4 & & & & 3 & 30 & 22 & 35 & 134 \\
\hline & $14-289$ & & 32 & & 35 & & & 9 & & 35 & & 34 & 145 \\
\hline & $14-33$ & & & 6 & & & & & & 32 & 28 & 21 & 87 \\
\hline & $14-63$ & 1 & 33 & 6 & 32 & 35 & & 33 & & 23 & & 34 & 197 \\
\hline & $14-73$ & 4 & 34 & & & & & & & 32 & & 36 & 106 \\
\hline & $14-74$ & & 30 & & 34 & 30 & & & & & & 32 & 126 \\
\hline & $14-76$ & & 29 & & & 33 & 5 & 33 & 12 & 32 & 33 & 31 & 208 \\
\hline & $14-82$ & & 35 & & 11 & & & & & 36 & 35 & 36 & 153 \\
\hline & Total & 14 & 329 & 58 & 273 & 133 & 30 & 184 & 89 & 373 & 235 & 397 & 2,115 \\
\hline
\end{tabular}

March) was also considered. Between the 1st and 2nd propagation periods, produced shoots were cut at the same 7-day intervals. For the two periods considered, percentage of cutting was calculated at the end of each period and not at each harvest.

Two types of traits were taken into account considering absolute and relative variables. The absolute variables were recorded per plant donor and are defined as follows: the absolute stock plant productivity (PROD) (number of collected shoots per plant donor) and the absolute propagation by cutting success (CUT) (number of cuttings alive 3 months after their transplantation). Using these absolute variables, the relative propagation by cutting success was estimated as RCUT $=$ CUT/PROD.

After the nursery experiment, cuttings were transplanted to the field in order to analyze the trend in variance components with age of growth and adaptive traits. The trees were planted in randomized bloc design with three replications (corresponding to three ramets per clone). Clones of the same fullsib family were planted in a 5 by 5 plot with a $3 \times 4 \mathrm{~m}$ spacing. The trees were measured for height and circumference at $1.3 \mathrm{~m}$ at 25 months. These growth variables were combined with the propagation variable to perform a multivariable analysis with statistical model (1) described in the "Data analysis" section.

Data analysis

The LMM was used to analyze the data collected at the nursery and in the field. A first model was used to estimate the proportions of male, female, and male by female interaction variance components in the total genetic variance and their interaction with the two propagation periods. The model 1 is described by the following equation:

$$
\begin{aligned}
y= & \mu \mathbf{1}_{\mathbf{n}}+\mathbf{X p}+Z_{\mathbf{m}} m+Z_{\mathbf{f}} f+Z_{\mathbf{m f}} \mathbf{m f}+Z_{\mathbf{p m}} \mathbf{p m}+Z_{\mathbf{p} \mathbf{p}} \mathbf{p f} \\
& +Z_{\mathbf{p m f}} \mathbf{p m f}+\varepsilon
\end{aligned}
$$

Where

$\boldsymbol{y} \quad$ is the vector of measurement related to each stock plant for PROD and CUT, individuals resulting from the cross of the male $m$ and a female $f$

$p \quad$ is the vector of fixed effect of propagation period

$m \quad$ is the vector of random effects of males, $m \sim N(0$, $\left.\sigma_{\mathrm{m}}^{2} \mathrm{Id}\right), 0$ is the vector of null values and Id is the identity matrix

$f \quad$ is the vector of random effects of females, $f \sim N(0$, $\sigma_{\mathrm{f}}^{2}$ Id)

$\mathrm{mf} \quad$ is the vector of random interaction effects between males and females, $\mathrm{mf} \sim N\left(0, \sigma_{\text {mf }}^{2}\right.$ Id $)$

$\mathrm{pm} \quad$ is the vector of random interaction effects between the male and propagation period, $\mathrm{pm} \sim N\left(0, \sigma^{2} \mathrm{p}_{\mathrm{m}} \mathrm{Id}\right)$

pf is the vector of random interaction effects between the female and propagation period, $\mathrm{pf} \sim N\left(0, \sigma^{2}{ }_{\mathrm{pf}} \mathrm{Id}\right)$

$\mathrm{pmf}$ is the random interaction effect between the family and propagation period, $\operatorname{pmf} \sim N\left(0, \sigma^{2}\right.$ pmf Id $)$

$\varepsilon \quad$ is the vector of random residual error, $\varepsilon \sim N\left(0, \sigma^{2}\right.$ Id $)$.

The model (1) was implemented using the following types of variables: (i) response variable used for $\boldsymbol{y}$ is the original variable without any transformation, (ii) response variable 
used for $\boldsymbol{y}$ is transformed by different functions $(\log (y)$ for PROD and logit, $\log [(1+y) /(1-y)]$, for CUT). For CUT, using original and transformed data, a weighted linear mixed model was used, with the variable PROD as weight.

In order to complete these first statistical approaches, the GLMM was used (Mc Cullah and Nelder 1989; Bolker et al. 2008). GLMM is an extension of the LMM to situations with a distribution other than normal, such as binomial and Poisson. It needs the specification of the distribution, together with a link function that connects the response to the explanatory variables of the linear model. For PROD, the distribution was Poisson and the link function was the natural logarithm. For CUT, the distribution was binomial and the link function was the logit. Thus, a realistic hypothesis for the PROD variable is the following:with

$$
\begin{aligned}
& Y \quad \text { random effects } \sim \text { Posson }(\lambda) \\
& \begin{aligned}
\log (\boldsymbol{\lambda})= & \boldsymbol{\mu} 1_{\boldsymbol{n}}+\boldsymbol{X} \boldsymbol{p}+\boldsymbol{Z}_{\boldsymbol{m}} \boldsymbol{m}+\boldsymbol{Z}_{\boldsymbol{f}} \boldsymbol{f}+\boldsymbol{Z}_{\mathrm{mf}} \mathrm{mf} \\
& +\boldsymbol{Z}_{\mathrm{pm}} \mathrm{pm}+\boldsymbol{Z}_{\mathrm{pf}} \mathrm{pf}+\boldsymbol{Z}_{\mathrm{pmf}} \mathrm{pmf}
\end{aligned}
\end{aligned}
$$

and $\lambda$ the Poisson parameter.

For the CUT proportion data, a realistic hypothesis is given by:

$Y \mid \operatorname{random}$ effects $\sim \operatorname{Binomial}(n, p)$

with

$$
\begin{aligned}
\log \left(\frac{\boldsymbol{p}}{1-\boldsymbol{p}}\right)= & \boldsymbol{\mu} 1_{\mathrm{n}}+\mathrm{Xp}+\boldsymbol{Z}_{\mathrm{m}} \boldsymbol{m}+\boldsymbol{Z}_{\mathrm{f}} \boldsymbol{f}+\boldsymbol{Z}_{\mathrm{mf}} \mathrm{mf} \\
& +\boldsymbol{Z}_{\mathrm{pm}} \mathrm{pm}+\boldsymbol{Z}_{\mathrm{pf}} \mathrm{pf}+\boldsymbol{Z}_{\mathrm{pmf}} \mathrm{pmf}
\end{aligned}
$$

and $p$ and $n$ the parameters of the binomial distribution.

The use of GLMM needs to consider the dispersion parameter $\varphi$ which is related to the variance of the distribution. In this study, our estimations were done by fixing $\varphi=1$ (i.e., no overdispersion) after preliminary analyses showing that the GLMM did not lead to overdispersion with our data.

A second mixed model, adapted from the animal model (Mrode and Thompson 2005; Piepho et al. 2008) was used to estimate correlations and to compare the selection accuracy.

$y=\boldsymbol{\mu} \mathbf{1}_{\mathbf{n}}+\mathbf{X p}+Z_{\mathrm{u}} u+Z_{\mathrm{fam}} \mathbf{f a m}+Z_{\mathrm{pu}} \mathrm{pu}+Z_{\mathrm{pfam}} \mathrm{pfam}+\varepsilon$

where $p$ is a vector fixed effect of propagation period, $u$ is a vector of random additive effects $u \sim \mathrm{N}\left(0, \sigma^{2}{ }_{\mathrm{a}} A\right)$ with $A$ the relationship matrix computed among individuals defined with the pedigree and fam is a vector of random family effects not explained by the additive effects, fam $\sim N\left(0, \sigma_{\mathrm{f}}^{2} \mathrm{Id}\right)$, pu is the vector of random interaction effects between the additive effect $u$ and propagation period, $\mathrm{pu} \sim N\left(0, \sigma_{\mathrm{pa}}^{2} \mathrm{Id}\right)$, pfam is the vector of random interaction effects between the family and the propagation period, pfam $\sim N\left(0, \sigma^{2}{ }_{p f} \mathrm{Id}\right), \varepsilon$ is the vector of random residual error, $\varepsilon \sim N\left(0, \sigma^{2} \mathrm{Id}\right)$. Variance components were estimated using Asreml version 3 (Gilmour et al. 2006) for both model 1 and 2 .

Variance components, heritability, and correlations

The relation between variance components and the classic model of quantitative genetics was used to calculate the following variances (Gallais 1990):

$$
\begin{aligned}
& \sigma_{\mathrm{Am}}^{2}=4 \times \sigma_{\mathrm{m}}^{2} \quad \text { is additive variance due to } \\
& \sigma_{\mathrm{Af}}^{2}=4 \times \sigma_{\mathrm{f}}^{2} \\
& \sigma^{2}{ }_{\mathrm{D}}=4 \times \sigma^{2} \text { fm } \\
& \sigma_{\mathrm{G}}^{2}=1 / 2\left(\sigma_{\mathrm{Am}}^{2}+\sigma_{\mathrm{Af}}^{2}\right)+\sigma^{2}{ }_{\mathrm{D}}
\end{aligned}
$$

For the model 1 using the original and the transformed variable and the LMM, the narrow- (ss) and broad- (sl) sense heritabilities were calculated using the classic formulas.

Narrow-sense heritability was given by:

$h_{\mathrm{ss}}^{2}=\frac{\sigma^{2} \mathrm{~A}}{\sigma^{2}{ }_{\mathrm{m}}+\sigma^{2} \mathrm{f}+\sigma^{2}{ }_{\mathrm{mf}}+\sigma^{2}{ }_{\mathrm{pm}}+\sigma_{\mathrm{pf}}^{2}+\sigma^{2} \mathrm{pmf}+\sigma^{2} \mathrm{e}}$

Broad-sense heritability was given by:

$H^{2} \mathrm{sl}=\frac{\sigma^{2} \mathrm{~A}+\sigma^{2} \mathrm{D}}{\sigma_{\mathrm{m}}^{2}+\sigma_{\mathrm{f}}^{2}+\sigma_{\mathrm{mf}}^{2}+\sigma_{\mathrm{pm}}^{2}+\sigma_{\mathrm{pf}}^{2}+\sigma_{\mathrm{pmf}}^{2}+\sigma^{2} \mathrm{e}}$

Using the GLMM approach, the heritability calculation depends on the type of variable. The heritability based on the link function (Nakagawa and Schielzeth 2010) has been considered

For PROD analysed with GLMM with a Poisson distribution and the log link, narrow- $\left(\mathrm{h}^{2} \mathrm{ss}\right)$ and broad$\left(\mathrm{H}^{2} \mathrm{sl}\right)$ sense heritabilities were then defined using the two following equations:

$h_{\mathrm{ss}}{ }^{2} \log =\frac{\sigma_{\mathrm{A}}^{2}}{\sigma^{2} \mathrm{~m}+\sigma^{2} \mathrm{f}+\sigma_{\mathrm{mf}}^{2}+\sigma_{\mathrm{pm}}^{2}+\sigma_{\mathrm{pf}}^{2}+\sigma^{2}{ }_{\mathrm{pmf}}+\varphi \ln \left(\frac{1}{\bar{y}_{\mathrm{g}}}+1\right)}$ 


$$
H_{\mathrm{sl}}{ }^{2} \log =\frac{\sigma_{\mathrm{A}}^{2}+\sigma_{\mathrm{D}}^{2}}{\sigma_{\mathrm{m}}^{2}+\sigma^{2} \mathrm{f}+\sigma_{\mathrm{mf}}^{2}+\sigma_{\mathrm{pm}}^{2}+\sigma_{\mathrm{pf}}^{2}+\sigma_{\mathrm{pmf}}^{2}+\varphi \ln \left(\frac{1}{\bar{y}_{\mathrm{g}}}+1\right)}
$$

with $\varphi$ being the dispersion parameter and $\bar{y}_{\mathrm{g}}$ the geometric mean of $y$.

For CUT, a GLMM was considered assuming a binomial distribution and the logit link, and the narrow- and broadsense heritabilities were calculated as follows:

$h_{\text {sslogit }}^{2}=\frac{\sigma^{2} \mathrm{~A}}{\sigma_{\mathrm{m}}^{2}+\sigma^{2}{ }_{\mathrm{f}}+\sigma_{\mathrm{mf}}^{2}+\sigma_{\mathrm{pm}}^{2}+\sigma_{\mathrm{pf}}^{2}+\sigma_{\mathrm{pmf}}^{2}+\varphi \pi^{2} / 3}$

$H^{2}{ }_{\text {sl }{ }_{\text {logit }}}=\frac{\sigma^{2} \mathrm{~A}+\sigma^{2} \mathrm{D}}{\sigma_{\mathrm{m}}^{2}+\sigma_{\mathrm{f}}^{2}+\sigma_{\mathrm{mf}}^{2}+\sigma^{2} \mathrm{pm}+\sigma_{\mathrm{pf}}^{2}+\sigma^{2} \mathrm{pmf}+\varphi \pi^{2} / 3}$

With $\varphi$ the dispersion parameter.

The additive $\left(\rho_{A}\right)$, dominance $\left(\rho_{D}\right)$, total genetic $\left(\rho_{G}\right)$, and environmental $\left(\rho_{E}\right)$ correlations between two traits $(x$ and $y)$ were estimated from a bivariate analysis using the individual model 2. The vectors for the two traits were stacked up and a covariance structure between the vectors of random effects was declared that made possible the estimation of the correlation coefficients.

As for univariate analysis, $\sigma^{2} x, \sigma^{2} y$ represent the variance of trait " $x$ " and " $y$ ", respectively, and cov $(x, y)$, the covariance between traits " $x$ " and " $y$ ". The coefficients of correlation were estimated as follows:

$\rho_{\mathrm{A}}=\frac{\operatorname{Cov}_{\mathrm{A}}(x, y)}{\sigma_{\mathrm{Ax}} \cdot \sigma_{\mathrm{Ay}}}$

$\rho_{\mathrm{D}}=\frac{\operatorname{Cov}_{\mathrm{D}}(x, y)}{\sigma_{\mathrm{Dx}} \cdot \sigma_{\mathrm{Dy}}}$

$\rho_{\mathrm{G}}=\frac{\operatorname{Cov}_{\mathrm{G}}(x, y)}{\sigma_{\mathrm{Gx}} \cdot \sigma_{\mathrm{Gy}}}$

$\rho_{\mathrm{e}}=\frac{\operatorname{Cov}_{\mathrm{e}}(x, y)}{\sigma_{\mathrm{ex}} \cdot \sigma_{\mathrm{ey}}}$
All the variances and co-variances associated with random effects were estimated by the restricted maximum likelihood (REML method) using ASReml version 3 (Gilmour et al. 2006). Standard errors of variances, heritabilities, and correlations were calculated with ASReml using a standard Taylor series approximation (Gilmour et al. 2006).

\section{Comparison of selection accuracy}

The impact of the different approaches on the selection accuracy was studied by comparison of ranking of the predicted genetic values and the prediction accuracy. As the populations of females and males (13 and 11 individuals, respectively) were too small to compare the ranking, this analysis was conducted with the hybrid population of stock plants $(2,115$ individuals) using the model 2.

The accuracy of the selection, $r$, generated by the three data analysis approaches (original variable with LMM, transformed variable with LMM, GLMM with dispersion coefficient fixed at one) and the model 2 was assessed by averaging the accuracy of the individual predicted breeding values $r_{\mathrm{i}}$ calculated with Eq. (11) for all the individuals.

$r_{\mathrm{i}}=\sqrt{1-\frac{s_{\mathrm{i}}^{2}}{\left(1+f_{\mathrm{i}}\right) \sigma_{\mathrm{a}}^{2}}}$

Where $s_{\mathrm{i}}^{2}$ is the 'prediction error variance' of predicted breeding values (Gilmour et al. 1995), $f_{\mathrm{i}}$ is the inbreeding coefficient for the ith individual, and $\sigma^{2}$ is the additive variance; $s_{\mathrm{i}}{ }^{2}$ and $f_{\mathrm{i}}$ were estimated with Asreml version 3 (Gilmour et al. 2006).

The comparison of ranking was done by estimating the Spearman coefficient of correlation among the different prediction approaches.

\section{Results}

Trends in propagation ability with stock plant age

The evolution of cutting production can be characterized by a first phase corresponding to the entry into production, which is not considered in this analysis. This phase was characterized by increased shoot production. After this first phase, we observed near-stabilization of PROD and CUT between the two propagation periods (Table 2 ), but some variables presented significant differences. The average of the two propagation periods was around $\mathrm{PROD}=7$ for the number of shoots produced per stock plant and $\mathrm{CUT}=6$ for the number of 
Table 2 Main statistics related to the propagation traits according to the two periods of propagation and to the growth traits of the cuttings planted in the field experimental design

\begin{tabular}{|c|c|c|c|c|c|c|c|c|c|}
\hline Trial & Trait & $\begin{array}{l}\text { Propagation } \\
\text { period }\end{array}$ & Mean & $\begin{array}{l}\text { Wald test } \\
\text { Period effect }\end{array}$ & SD & Min & Max & CV (\%) & $N$ \\
\hline \multirow[t]{6}{*}{ Nursery } & \multirow[t]{2}{*}{ PROD } & 1 & 8.71 & & 4.84 & 0 & 27 & 55 & 2,148 \\
\hline & & 2 & 6.03 & $P=0.001$ & 6.11 & 0 & 30 & 100 & 2,093 \\
\hline & \multirow[t]{2}{*}{ CUT } & 1 & 5.37 & & 3.85 & 0 & 21 & 72 & 2,115 \\
\hline & & 2 & 6.82 & $P=0.44$ & 4.58 & 0 & 26 & 95 & 1,366 \\
\hline & \multirow[t]{2}{*}{ RCUT (\%) } & 1 & 64.37 & & 21.25 & 13 & 100 & 33 & 1,862 \\
\hline & & 2 & 74.88 & $P=0.032$ & 21.85 & 8 & 100 & 29 & 1,317 \\
\hline \multirow[t]{2}{*}{ Field } & Ht25 (m) & - & 9.11 & - & 3.08 & 0.3 & 17.8 & 33.79 & 3,358 \\
\hline & $\mathrm{C} 25(\mathrm{~cm})$ & - & 22.47 & - & 9.18 & 0 & 46.8 & 40.89 & 3,358 \\
\hline
\end{tabular}

PROD number of collected shoots per plant donor, CUT number of cuttings alive 3 months after shoot transplantation, $R C U T=C U T / P R O D$ propagation success, $H t 25$ tree height at 25 months, $C 25$ tree circumference at 25 months

cuttings. These absolute values correspond to the mean percentage $\mathrm{RCUT}=69 \%$.

The difference between these two periods for the PROD (from 8.71 to 6.03 ), and the relative cutting success RCUT (from 64.4 to $74.9 \%$ ) were significant at $p=0.05$, demonstrating a propagation period effect for these variables. The coefficient of variation (CV) showed high values for PROD and increased during the propagation process from 55 to $100 \%$. The same trend was observed with CUT, with an increase from 72 to $95 \%$. These high CV values are explained by the much skewed distribution of these variables. For RCUT, the $\mathrm{CV}$ was stable around $30 \%$. For growth variables, it varied between 34 and $41 \%$.

\section{Comparison of variance components and their ratio}

Phenotypic variance of the different traits was partitioned into male, female, and male-female interaction, their interaction with the propagation phase and the residual variance using the model (1). (All the estimates of the variances and their standard error are given in Tables 3 and 4.)

As expected, due to the different scales used to define variables, the genetic variance components, whatever the random effect, varied with the type of model (LMM or GLMM) and the variable transformation (Table 3 ). For the shoot production PROD, for example, $\sigma^{2}{ }_{\mathrm{m}}=2.93$ with LMM and $\sigma_{\mathrm{m}}^{2}=$ 0.078 with LMM and transformed variable LOGPROD, $\sigma_{\mathrm{m}}^{2}=$ 0.136 with GLMM and $\psi=1$. Whatever the type of variable and the model, the residual variance $\sigma^{2}$ e was preponderant, showing the strong environmental effect in the propagation process (assuming a no epistatic effect). Variance due to the female was smaller than variance due to the male or to the male-female interaction. The variances related to the period by genetic effect interactions were preponderant for some genetic effects like female and male-female interaction. As a result, the estimated additive and dominance variances varied with variable transformation and models, for example $\sigma_{\mathrm{A}}^{2}=5.863$ with LMM, $\sigma_{\mathrm{A}}^{2}=0.186$ with LMM and LOGPROD and $\sigma_{\mathrm{A}}^{2}=0.272$ with GLMM and $\psi=1$. Although the variance component estimates varied according to the model and variable transformation, the ratio of dominance to additive genetic variance varied to a lesser extent and was close to one depending on the model and transformation, varying from $\sigma^{2}{ }_{\mathrm{D}} / \sigma_{\mathrm{A}}^{2}=1.435$ with $\mathrm{LMM}$ without transformation to $\sigma^{2}{ }_{\mathrm{D}} /$ $\sigma^{2}{ }_{\mathrm{A}}=1.068$ with GLMM and $\psi=1$ (Table 3 ). Narrow- and broad-sense heritabilities varied according to the model. For example, $h_{\text {ss }}^{2}=0.182$ and $H^{2}{ }_{s l}=0.443$ with LMM and the nontransformed variables, but $h_{\mathrm{ss}}^{2}=0.431$ and $H^{2}{ }_{\mathrm{sl}}=0.839$ with GLMM and log link equation (Eqs. 3 and 4) (Table 3). As expected, broad-sense heritability values were higher than narrow-sense, but both showed a similar trend according to the model and the equation used (Table 3).

Similar results were observed with the CUT variable (or RCUT) (Table 4): the variance component estimates varied with the model and the variable transformation, the residual variable was preponderant, the male variance was higher than the female variance, and the dominance to additive variance ratio varied between 0.907 and 1.571. As for PROD, estimated broad- and narrow-sense heritabilities for CUT were smaller with LMM $\left(h^{2}{ }_{\mathrm{ss}}=0.094\right.$ and $\left.H^{2}{ }_{\mathrm{sl}}=0.180\right)$ than with GLMM model $\left(h_{\mathrm{ss}}^{2}=0.199\right.$ and $\left.H_{\mathrm{sl}}^{2}=0.421\right)$. They were smaller than for PROD with both LMM and GLMM model.

Genetic and environmental correlations

To avoid bias due to autocorrelation between the number of shoots and the number of cuttings, the correlations were calculated between the number of shoots (PROD) and the percentage of cutting success (RCUT). For original variables (PROD with RCUT) and transformed variables (logPROD and logitRCUT), the correlations were higher than 0.5 , respectively $\rho_{A}=0.98$ and $\rho_{A}=0.96$ for additive, $\rho_{D}=0.71$ and 
Table 3 Estimates of variance components and genetic parameters for PROD with the parent model (model 1)

\begin{tabular}{|c|c|c|c|c|c|c|c|c|}
\hline \multicolumn{2}{|c|}{ Parent model (1) } & \multicolumn{4}{|l|}{ LMM } & \multicolumn{3}{|l|}{ GLMM } \\
\hline \multirow[t]{2}{*}{ PROD } & \multirow[b]{2}{*}{ Component/parameter } & \multicolumn{2}{|l|}{ PROD } & \multicolumn{2}{|l|}{ LOGPROD } & \multicolumn{3}{|c|}{ PROD POISSON } \\
\hline & & Estimate & SD & Estimate & SD & Estimate & SD & $\log$ \\
\hline & $\sigma^{2} \mathrm{~m}$ & $2.931 \mathrm{E}+00$ & $2.864 \mathrm{E}+00$ & $7.808 \mathrm{E}-02$ & $1.821 \mathrm{E}-03$ & $1.306 \mathrm{E}-01$ & $6.801 \mathrm{E}-03$ & \\
\hline & $\sigma^{2} \mathrm{f}$ & $2.492 \mathrm{E}-06$ & $3.044 \mathrm{E}-15$ & $1.482 \mathrm{E}-02$ & $1.546 \mathrm{E}-04$ & $5.567 \mathrm{E}-03$ & $1.239 \mathrm{E}-03$ & \\
\hline & $\sigma^{2} \mathrm{pm}$ & $1.090 \mathrm{E}-01$ & $9.151 \mathrm{E}-02$ & $4.910 \mathrm{E}-03$ & $2.806 \mathrm{E}-05$ & $3.731 \mathrm{E}-02$ & $9.954 \mathrm{E}-04$ & \\
\hline & $\sigma^{2} \mathrm{pf}$ & $1.121 \mathrm{E}+00$ & $3.653 \mathrm{E}-01$ & $6.405 \mathrm{E}-03$ & $3.432 \mathrm{E}-05$ & $6.616 \mathrm{E}-02$ & $1.730 \mathrm{E}-03$ & \\
\hline & $\sigma^{2} \mathrm{mf}$ & $2.104 \mathrm{E}+00$ & $6.630 \mathrm{E}-01$ & $4.324 \mathrm{E}-02$ & $1.625 \mathrm{E}-04$ & $7.270 \mathrm{E}-02$ & $1.425 \mathrm{E}-03$ & \\
\hline & $\sigma^{2} \mathrm{pmf}$ & $2.882 \mathrm{E}+00$ & $4.942 \mathrm{E}-01$ & $1.855 \mathrm{E}-02$ & $5.327 \mathrm{E}-05$ & $1.938 \mathrm{E}-01$ & $1.595 \mathrm{E}-03$ & \\
\hline & $\sigma^{2} \mathrm{e}$ & $2.307 \mathrm{E}+01$ & $2.609 \mathrm{E}-01$ & $3.578 \mathrm{E}-01$ & $7.70 \mathrm{E}-05$ & $1.000 \mathrm{E}+00$ & $0.000 \mathrm{E}+00$ & \\
\hline & $\sigma^{2} \mathrm{~A}$ & $5.863 \mathrm{E}+00$ & & $0.186 \mathrm{E}+00$ & & $0.272 \mathrm{E}+00$ & & \\
\hline & $\sigma^{2} \mathrm{D}$ & $8.415 \mathrm{E}+00$ & & $0.173 \mathrm{E}+00$ & & $0.291 \mathrm{E}+00$ & & \\
\hline & $\sigma^{2} \mathrm{P}$ & $32.218 \mathrm{E}+00$ & & $0.524 \mathrm{E}+00$ & & & & $0.632 \mathrm{E}+00$ \\
\hline & $\sigma^{2} \mathrm{D} / \sigma^{2} \mathrm{~A}$ & $1.435 \mathrm{E}+00$ & & $0.931 \mathrm{E}+00$ & & & & $1.068 \mathrm{E}+00$ \\
\hline & $h^{2} \mathrm{ss}$ & $0.182 \mathrm{E}+00$ & & $0.355 \mathrm{E}+00$ & & & & $0.431 \mathrm{E}+00$ \\
\hline & $H^{2} \mathrm{sl}$ & $0.443 \mathrm{E}+00$ & & $0.685 \mathrm{E}+00$ & & & & $0.891 \mathrm{E}+00$ \\
\hline
\end{tabular}

PROD number of collected shoots per plant donor, $£$ Log heritability calculated using Eqs. ( 3 and 4) ( $\psi=1$; Y geometric mean $\left.\bar{y}_{\mathrm{g}}=9.010\right)$

$\rho_{D}=0.60$ for dominance, $\rho_{G}=0.69$ and $\rho_{G}=0.57$ for total genetic, showing the strong genetic relationship between those two traits. The residual correlations $\rho_{e}$ were small, included in $[-0.010 ; 0.15]$ showing a quasi-independence of environmental effects on both traits.
The magnitude of the correlations between shoot production (PROD) and field growth (height and circumference at 25 months) differed according to the genetic effect, but was generally low to moderate and included in $[-0.5 ; 0.5]$, and a very similar pattern was observed for LOGPROD (Table 5).

Table 4 Estimates of variance components and genetic parameters for CUT with the parent model (model 1)

\begin{tabular}{|c|c|c|c|c|c|c|c|}
\hline Parent model (1) & \multicolumn{4}{|l|}{ LMM } & \multirow{2}{*}{\multicolumn{3}{|c|}{$\frac{\text { GLMM }}{\text { CUT LOGIT }}$}} \\
\hline \multirow[b]{2}{*}{ Component/parameter } & \multicolumn{2}{|l|}{ RCUT } & \multicolumn{2}{|l|}{ LOGITCUT } & & & \\
\hline & Estimate & SD & Estimate & $\mathrm{SD}$ & Estimate & SD & ${ }^{\mathrm{a}}$ Logit \\
\hline$\sigma^{2} \mathrm{~m}$ & $1.640 \mathrm{E}+02$ & $8.695 \mathrm{E}+03$ & $3.646 \mathrm{E}-02$ & $4.850 \mathrm{E}-04$ & $4.655 \mathrm{E}-01$ & $8.038 \mathrm{E}-02$ & \\
\hline$\sigma^{2} \mathrm{f}$ & $4.519 \mathrm{E}+00$ & $6.417 \mathrm{E}+02$ & $2.128 \mathrm{E}-03$ & $6.715 \mathrm{E}-05$ & $8.012 \mathrm{E}-09$ & $0.000 \mathrm{E}+00$ & \\
\hline$\sigma^{2} \mathrm{pm}$ & $1.630 \mathrm{E}+00$ & $1.604 \mathrm{E}+02$ & $1.655 \mathrm{E}-10$ & $1.656 \mathrm{E}-23$ & $6.153 \mathrm{E}-02$ & $5.473 \mathrm{E}-03$ & \\
\hline$\sigma^{2} \mathrm{pf}$ & $2.516 \mathrm{E}+01$ & $5.283 \mathrm{E}+02$ & $8.185 \mathrm{E}-03$ & $4.594 \mathrm{E}-05$ & $9.842 \mathrm{E}-02$ & $4.622 \mathrm{E}-03$ & \\
\hline$\sigma^{2} \mathrm{mf}$ & $7.646 \mathrm{E}+01$ & $1.642 \mathrm{E}+03$ & $3.030 \mathrm{E}-02$ & $1.519 \mathrm{E}-04$ & $2.595 \mathrm{E}-01$ & $1.624 \mathrm{E}-02$ & \\
\hline$\sigma^{2} \mathrm{pmf}$ & $1.517 \mathrm{E}+02$ & $1.330 \mathrm{E}+03$ & $3.830 \mathrm{E}-02$ & $8.104 \mathrm{E}-05$ & $4.982 \mathrm{E}-01$ & $1.372 \mathrm{E}-02$ & \\
\hline$\sigma^{2} \mathrm{e}$ & $3.153 \mathrm{E}+03$ & $6.015 \mathrm{E}+03$ & $9.756 \mathrm{E}-01$ & $5.751 \mathrm{E}-04$ & $1.000 \mathrm{E}+00$ & $0.000 \mathrm{E}+00$ & \\
\hline$\sigma^{2} \mathrm{~A}$ & $337.084 \mathrm{E}+00$ & & $0.077 \mathrm{E}+00$ & & $0.931 \mathrm{E}+00$ & & \\
\hline$\sigma^{2} \mathrm{D}$ & $305.828 \mathrm{E}+00$ & & $0.121 \mathrm{E}+00$ & & $1.038 \mathrm{E}+00$ & & \\
\hline$\sigma^{2} \mathrm{P}$ & $3576.487 \mathrm{E}+00$ & & $1.091 \mathrm{E}+00$ & & & & $4.673 \mathrm{E}+00$ \\
\hline$\sigma^{2} \mathrm{D} / \sigma^{2} \mathrm{~A}$ & $0.907 \mathrm{E}+00$ & & $1.571 \mathrm{E}+00$ & & & & $1.115 \mathrm{E}+00$ \\
\hline$h^{2} \mathrm{ss}$ & $0.094 \mathrm{E}+00$ & & $0.071 \mathrm{E}+00$ & & & & $0.199 \mathrm{E}+00$ \\
\hline$H^{2} \mathrm{sl}$ & $0.180 \mathrm{E}+00$ & & $0.182 \mathrm{E}+00$ & & & & $0.421 \mathrm{E}+00$ \\
\hline
\end{tabular}

${ }^{\text {a }}$ Logit heritability calculated using Eqs. (7 and 8) $(\psi=1)$

CUT the number of cuttings produced per stock plant 
Table 5 Genetic correlation estimates between propagation variables and juvenile growth of the cutting in the field trial. The environmental correlation $\left(\rho_{\mathrm{E}}\right)$, the additive correlation $\left(\rho_{\mathrm{A}}\right)$, the dominance correlation $\left(\rho_{\mathrm{D}}\right)$, and the total genetic correlation $\left(\rho_{\mathrm{G}}\right)$

\begin{tabular}{|c|c|c|c|c|c|c|c|c|c|}
\hline \multicolumn{5}{|c|}{ Original variable } & \multicolumn{5}{|c|}{ Transformed variable } \\
\hline Nursery & Field & Type of correlation & $R$ & SD & Nursery & Field & Type of correlation & $r$ & SD \\
\hline PROD & HT25 & $\rho_{\mathrm{E}}$ & 0.080 & 0.028 & LOGPROD & HT25 & $\rho_{\mathrm{E}}$ & 0.081 & 0.028 \\
\hline PROD & HT25 & $\rho_{\mathrm{A}}$ & -0.401 & 0.418 & LOGPROD & HT25 & $\rho_{\mathrm{A}}$ & -0.353 & 0.435 \\
\hline PROD & HT25 & $\rho_{\mathrm{D}}$ & 0.406 & 0.169 & LOGPROD & HT25 & $\rho_{\mathrm{D}}$ & 0.419 & 0.165 \\
\hline PROD & HT25 & $\rho_{\mathrm{G}}$ & 0.197 & 0.158 & LOGPROD & HT25 & $\rho_{\mathrm{G}}$ & 0.227 & 0.155 \\
\hline PROD & $\mathrm{C} 25$ & $\rho_{\mathrm{E}}$ & 0.068 & 0.028 & LOGPROD & $\mathrm{C} 25$ & $\rho_{\mathrm{E}}$ & 0.072 & 0.028 \\
\hline PROD & $\mathrm{C} 25$ & $\rho_{\mathrm{A}}$ & -0.302 & 0.410 & LOGPROD & $\mathrm{C} 25$ & $\rho_{\mathrm{A}}$ & -0.240 & 0.421 \\
\hline PROD & $\mathrm{C} 25$ & $\rho_{\mathrm{D}}$ & 0.459 & 0.195 & LOGPROD & $\mathrm{C} 25$ & $\rho_{\mathrm{D}}$ & 0.450 & 0.195 \\
\hline PROD & $\mathrm{C} 25$ & $\rho_{\mathrm{G}}$ & 0.214 & 0.174 & LOGPROD & $\mathrm{C} 25$ & $\rho_{\mathrm{G}}$ & 0.234 & 0.170 \\
\hline RCUT & HT25 & $\rho_{\mathrm{E}}$ & 0.009 & 0.028 & LOGITCUT & HT25 & $\rho_{\mathrm{E}}$ & 0.022 & 0.028 \\
\hline RCUT & HT25 & $\rho_{\mathrm{A}}$ & 0.255 & 0.869 & LOGITCUT & HT25 & $\rho_{\mathrm{A}}$ & 0.258 & 0.814 \\
\hline RCUT & HT25 & $\rho_{\mathrm{D}}$ & -0.106 & 0.176 & LOGITCUT & HT25 & $\rho_{\mathrm{D}}$ & -0.074 & 0.176 \\
\hline RCUT & HT25 & $\rho_{\mathrm{G}}$ & -0.059 & 0.145 & LOGITCUT & HT25 & $\rho_{\mathrm{G}}$ & -0.032 & 0.145 \\
\hline RCUT & $\mathrm{C} 25$ & $\rho_{\mathrm{E}}$ & 0.001 & 0.028 & LOGITCUT & $\mathrm{C} 25$ & $\rho_{\mathrm{E}}$ & 0.016 & 0.028 \\
\hline RCUT & $\mathrm{C} 25$ & $\rho_{\mathrm{A}}$ & 0.356 & 0.862 & LOGITCUT & $\mathrm{C} 25$ & $\rho_{\mathrm{A}}$ & 0.470 & 1.616 \\
\hline RCUT & $\mathrm{C} 25$ & $\rho_{\mathrm{D}}$ & -0.284 & 0.203 & LOGITCUT & $\mathrm{C} 25$ & $\rho_{\mathrm{D}}$ & -0.249 & 0.205 \\
\hline RCUT & $\mathrm{C} 25$ & $\rho_{\mathrm{G}}$ & -0.158 & 0.159 & LOGITCUT & $\mathrm{C} 25$ & $\rho_{\mathrm{G}}$ & -0.143 & 0.157 \\
\hline
\end{tabular}

$P R O D$ number of collected shoots per plant donor, $C U T$ number of cuttings alive 3 months after shoot transplantation, $R C U T=C U T / P R O D$ propagation success

The environmental correlation $\left(\rho_{e}\right)$ was low, the additive correlation $\left(\rho_{A}\right)$ was negative but the standard error was high, showing a very poor estimation of this parameter, the dominance correlation $\left(\rho_{D}\right)$ was positive and the total genetic correlation $\left(\rho_{G}\right)$ was rather small. For RCUT and LOGITCUT, the correlations were generally smaller than for PROD (Table 5) and a large standard error was observed for the additive effect.

Impact of variable transformation and models on selection accuracy

The impact of the three different approaches with individual model and pedigree (model 2) (LMM with original and transformed variable and GLMM) on the genetic parameters is illustrated in the Tables 6 and 7. For PROD (Table 6), the results are consistent with the family model (model 1). For CUT (Table 7), the additive variance showed smaller estimates and the dominance variance showed very high estimates (and as a consequence the $\sigma^{2}{ }_{\mathrm{D}} / \sigma^{2}$ A ratio was also very high). This may be caused by the very unbalanced design for this variable due to the numerous missing data in the second period (when PROD $=0$, CUT is considered as missing).

In our results, a higher accuracy corresponded to a higher narrow-sense heritability which is expected when using the same LMM model (Mrode and Thompson 2005). For example, the PROD variable which showed a higher accuracy than
CUT, presented higher narrow-sense heritability (Tables 6 and 7). For PROD, the accuracy obtained with the three approaches showed higher accuracies using LMM with original and transformed variable ( $r=0.69$ and $r=0.74$, respectively) than with GLMM $(r=0.46)$ which showed also a smaller narrow-sense heritability (Table 6). For CUT, the differences between the three approaches were small (varying from $r=$ 0.32 to $r=0.35)$ and the narrow-sense heritabilities $\left(h^{2} \mathrm{ss}\right)$ were close (Table 7). These results are illustrated by significant rank correlations between the methods for predicted values, higher for CUT, varying from 0.920 to 0.998 , than for PROD, varying from 0.752 to 0.944 and by Fig. 1 .

However, comparison between LMM and GLMM must be done with caution as accuracy and heritabilities depend on completely different assumptions of the background error, and as they will estimate $\sigma_{\text {A }}^{2}$ differently, as they in one sense depend on internal transformations (as the logit or log link) that changes the scale.

\section{Discussion}

Trends in propagation ability with stock plant age

Cutting mortality was much higher in the dry season (36\%) (First propagation period) than in the rainy season $(25 \%)$ 
Table 6 Estimates of variance components and genetic parameters with individual model (2) for the PROD variable

\begin{tabular}{|c|c|c|c|c|c|c|c|}
\hline \multirow{3}{*}{$\begin{array}{l}\text { Individual tree model } \\
\text { PROD } \\
\text { Component/parameter }\end{array}$} & \multicolumn{4}{|l|}{ LMM } & \multirow{2}{*}{\multicolumn{3}{|c|}{$\frac{\text { GLMM }}{\text { PROD Poisson }}$}} \\
\hline & \multicolumn{2}{|l|}{ PROD } & \multicolumn{2}{|l|}{ LOGPROD } & & & \\
\hline & Estimate & SD & Estimate & SD & Estimate & SD & Log \\
\hline$\sigma^{2} \mathrm{f}$ & $1.846 \mathrm{E}+00$ & $6.569 \mathrm{E}-01$ & $3.896 \mathrm{E}-02$ & $1.627 \mathrm{E}-04$ & $7.024 \mathrm{E}-02$ & $1.43 \mathrm{E}-03$ & \\
\hline$\sigma^{2} \mathrm{pf}$ & $3.049 \mathrm{E}+00$ & $5.062 \mathrm{E}-01$ & $2.325 \mathrm{E}-02$ & $5.805 \mathrm{E}-05$ & $1.782 \mathrm{E}-01$ & $1.54 \mathrm{E}-03$ & \\
\hline$\sigma^{2} \mathrm{a}$ & $8.448 \mathrm{E}+00$ & $1.034 \mathrm{E}+00$ & $1.940 \mathrm{E}-01$ & $4.032 \mathrm{E}-04$ & $1.431 \mathrm{E}-01$ & $6.80 \mathrm{E}-04$ & \\
\hline$\sigma^{2} \mathrm{pa}$ & $2.466 \mathrm{E}+00$ & $2.234 \mathrm{E}+00$ & $2.203 \mathrm{E}-02$ & $2.783 \mathrm{E}-04$ & $6.682 \mathrm{E}-01$ & $1.10 \mathrm{E}-03$ & \\
\hline$\sigma^{2} \mathrm{e}$ & $1.758 \mathrm{E}+01$ & $8.884 \mathrm{E}-01$ & $2.505 \mathrm{E}-01$ & $1.703 \mathrm{E}-04$ & $1.000 \mathrm{E}+00$ & $0.000 \mathrm{E}+00$ & \\
\hline$\sigma^{2} \mathrm{~A}$ & $8.448 \mathrm{E}+00$ & $1.940 \mathrm{E}-01$ & & & $1.431 \mathrm{E}-01$ & & \\
\hline$\sigma^{2} \mathrm{D}$ & $7.383 \mathrm{E}+00$ & $1.558 \mathrm{E}-01$ & & & $2.810 \mathrm{E}-01$ & & \\
\hline$\sigma^{2} \mathrm{P}$ & $3.339 \mathrm{E}+01$ & $5.287 \mathrm{E}-01$ & & & & & $1.185 \mathrm{E}+00$ \\
\hline$\sigma^{2} \mathrm{D} / \sigma^{2} \mathrm{~A}$ & $8.739 \mathrm{E}-01$ & $8.034 \mathrm{E}-01$ & & & & & $1.964 \mathrm{E}+00$ \\
\hline$h^{2} \mathrm{ss}$ & $2.530 \mathrm{E}-01$ & $3.669 \mathrm{E}-01$ & & & & & $1.207 \mathrm{E}-01$ \\
\hline$H^{2} \mathrm{sl}$ & $4.741 \mathrm{E}-01$ & $6.617 \mathrm{E}-01$ & & & & & $0.358 \mathrm{E}+00$ \\
\hline
\end{tabular}

PROD number of collected shoots per plant donor, $\log$ heritability calculated using Eqs. ( 3 and 4$)\left(\psi=1\right.$; Y geometric mean $\left.\bar{y}_{\mathrm{g}}=9.010\right)$

(Second propagation period). At the same time, we observed an increase in cutting success from the first to the second period (64 and $75 \%$, respectively). As noticed above, these two periods corresponded to the two main climatic seasons in southern Congo. Environmental conditions (temperature, light, air moisture) are more suitable for propagation in the second period (rainy season) (Mankessi et al. 2011), and this may explain the greater cutting success. It is well known that one of the most marked environmental effects on shoot production and cutting success is season (light, temperature, moisture, fungus attack, etc.). Its effect has been shown for various plants (Rauter 1983; Monteuuis et al. 1995; Teklehaimanot et al. 2004; Bhardwaj and Mishra 2005; Danthu et al. 2008). The improvement of CUT and RCUT during the second propagation period is due in part to the season effect, but is not the only cause of variation in shoot production and cutting success, other causes include environmental risks, physiological age, and a potential operator effect.

Table 7 Estimates of variance components and genetic parameters with individual model (model 2) for the CUT variable

\begin{tabular}{|c|c|c|c|c|c|c|c|c|}
\hline \multirow{3}{*}{$\begin{array}{l}\text { Individual tree model } \\
\text { CUT }\end{array}$} & \multicolumn{5}{|l|}{ LMM } & \multirow{2}{*}{\multicolumn{3}{|c|}{$\begin{array}{l}\text { GLMM } \\
\text { CUT LOGIT } \psi=1\end{array}$}} \\
\hline & \multicolumn{2}{|l|}{ RCUT } & \multicolumn{3}{|l|}{ LOGITCUT } & & & \\
\hline & Component & Estimate & SD & Estimate & SD & Estimate & SD & ${ }^{\mathrm{a}}$ Logit \\
\hline & $\sigma^{2} \mathrm{f}$ & $1.030 \mathrm{E}+02$ & $2.048 \mathrm{E}+03$ & $1.857 \mathrm{E}-02$ & $1.10 \mathrm{E}-04$ & $3.547 \mathrm{E}-01$ & $1.810 \mathrm{E}-02$ & \\
\hline & $\sigma^{2} \mathrm{pf}$ & 158.081 & $1.581 \mathrm{E}+02$ & $1.400 \mathrm{E}+03$ & $4.248 \mathrm{E}-02$ & $4.08 \mathrm{E}-01$ & $4.082 \mathrm{E}-01$ & \\
\hline & $\sigma^{2} \mathrm{a}$ & $3.752 \mathrm{E}+01$ & $3.867 \mathrm{E}+02$ & $1.581 \mathrm{E}-02$ & $4.02 \mathrm{E}-05$ & $9.246 \mathrm{E}-02$ & $2.515 \mathrm{E}-03$ & \\
\hline & $\sigma^{2} \mathrm{pa}$ & 128.374 & $1.284 \mathrm{E}+02$ & $1.078 \mathrm{E}+03$ & $1.737 \mathrm{E}-01$ & 0.500224 & $5.002 \mathrm{E}-01$ & \\
\hline & $\sigma^{2} \mathrm{e}$ & $2.411 \mathrm{E}+03$ & $1.874 \mathrm{E}+04$ & $1.269 \mathrm{E}-01$ & $6.35 \mathrm{E}-04$ & $1.000 \mathrm{E}+00$ & $0.000 \mathrm{E}+00$ & \\
\hline & $\sigma^{2} \mathrm{~A}$ & $3.752 \mathrm{E}+01$ & & $1.581 \mathrm{E}-02$ & & $9.246 \mathrm{E}-02$ & & \\
\hline & $\sigma^{2} \mathrm{D}$ & $4.119 \mathrm{E}+02$ & & $7.428 \mathrm{E}-02$ & & $1.419 \mathrm{E}+00$ & & \\
\hline & $\sigma^{2} \mathrm{P}$ & $2.838 \mathrm{E}+03$ & & $3.775 \mathrm{E}-01$ & & & & $4.645 \mathrm{E}+00$ \\
\hline & $\sigma^{2} \mathrm{D} / \sigma^{2} \mathrm{~A}$ & $1.098 \mathrm{E}+01$ & & $4.699 \mathrm{E}+00$ & & & & $1.534 \mathrm{E}+01$ \\
\hline & $h^{2} \mathrm{ss}$ & $1.322 \mathrm{E}-02$ & & $4.187 \mathrm{E}-02$ & & & & $1.990 \mathrm{E}-02$ \\
\hline & $H^{2} \mathrm{sl}$ & $1.583 \mathrm{E}-01$ & & $2.386 \mathrm{E}-01$ & & & & $3.253 \mathrm{E}-01$ \\
\hline
\end{tabular}

${ }^{\text {a }}$ Logit heritability calculated using Eqs. 7 and 8$)(\psi=1)$

CUT the number of cuttings produced per stock plant 
(a) PROD variable
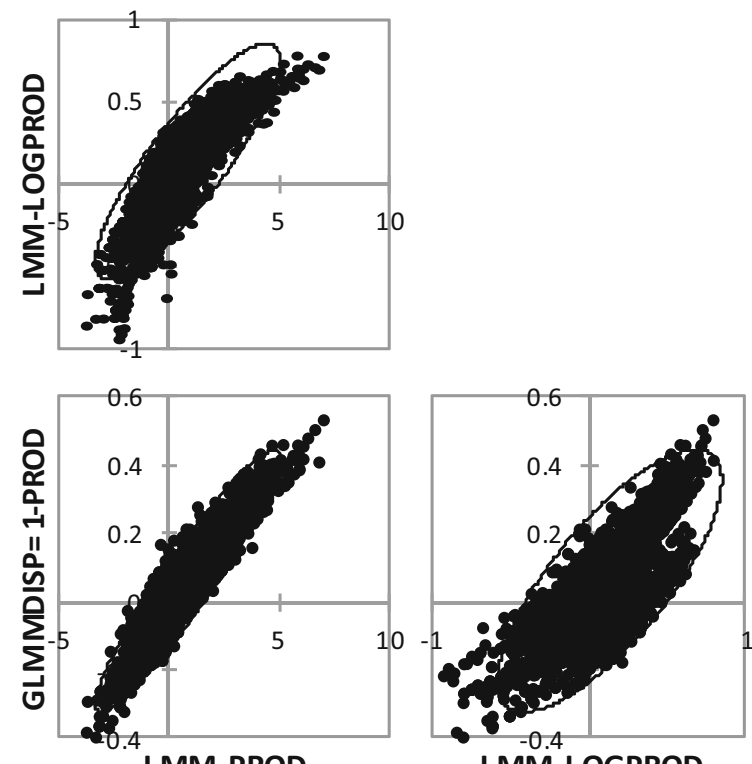

LMM-LOGPROD

Fig. 1 Correlation between the predicted values obtained with the three different approaches and model (2). $X$ axis $-L M M$ predicted values assessed with linear mixed model and original variable; $L M M-L O G$ and $L M M-L O G I T$ predicted values assessed with linear mixed model and

Before the first propagation period, the stock plants were attacked by Leptocibe invasa (Fisher \& LaSalle, Hymenoptera: Eulophidae), which had the direct effect of inducing a high number of poorly developed cuttings with weak rooting ability. As the prevalence of L. invasa decreased, the quality of cutting production improved. So, during the second propagation period, shoots became more suitable and the operator had a broader range of choice, thus introducing a selection factor, which may explain the increased cutting success during this period.

The physiological age effect can have a negative impact on cutting success. Maturation of plant material (aging of meristem) leads to a reduction in rooting ability (Foster et al. 1981; Bonga 1982; Marino 1982; Wareing 1987; Hackett 1985, 1988; Greenwood and Hutchison 1993; Poupard et al. 1994; Hamann 1995; Ruaud et al. 1999). For example, Marino (1982) has shown with southern pines that rooting remains active during the first 3 years for ground donors plant. In the case of extensive stock plants of E. urophylla $\times$ E. grandis, in humid tropical conditions, the length of this active period remains unknown. Cutting success improves with the age of stock plants when shoots are collected during the first 2 years (Mankessi et al. 2011). This was the case with our experiments, which explains why an older stock plant combined with a more favorable season (rainy season: better conditions in terms of light and temperature) led to a higher percentage of cutting success.

(b) CUT variable
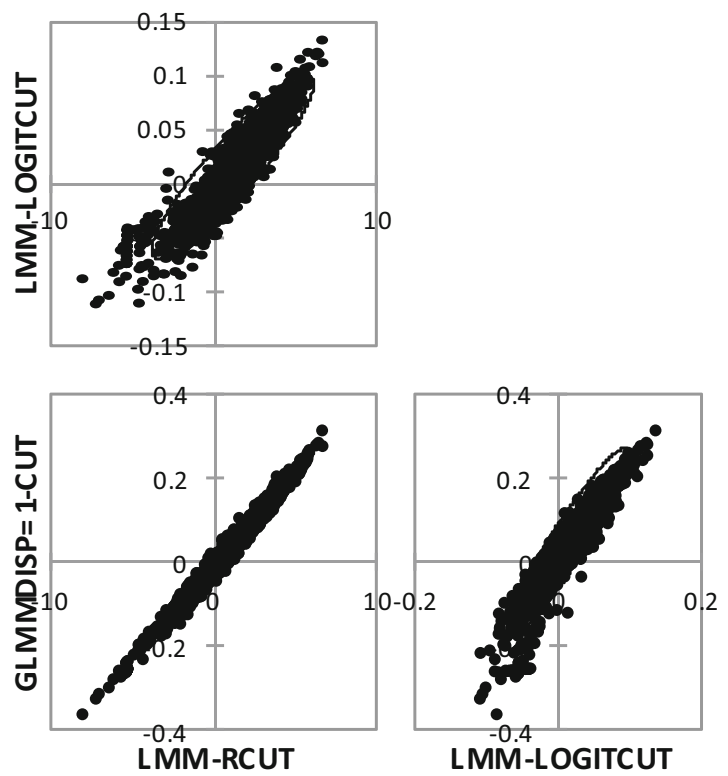

transformed variables. Yaxis - GLMMDISP $=1$ predicted values assessed with generalized linear mixed model and dispersion parameter equal to one; $L M M-L O G$ predicted values assessed with linear mixed model and transformed variables

Impact of variable transformation on variance component, heritability, and selection accuracy

The transformation of non-Gaussian data was used to confirm the LMM which assumes that both random effects and residuals are normally distributed. We used an a priori transformation for the count variable (LOG) and the proportion variable (LOGIT). Examination of the distributions of the residual showed that the transformation with LOGIT (CUT) improved the Gaussian distribution and independence of residuals, whereas the impact was not noticeable for PROD with the logarithmic transformation (results not shown). These transformations led to different estimates of variance components and ratios (Tables 3, 4, 6, and 7). This result was expected because the parameters were estimated on the transformed scale and not on the original scale. Differences between estimated heritability on the original and transformed scales have been reported before (Browne et al. 2005; Carrasco and Jover 2005). The impact of variable transformation on selection accuracy was relatively limited.

Impact of statistical model on variance component, heritability, and selection accuracy

In this study, we used the variables (CUT and PROD) to understand the genetic basis of propagation ability. Using such variables in breeding programs has required the development of adequate statistical methods for the estimation of 
parameters and the prediction of breeding values because these variables do not follow a normal distribution (Garcia et al. 2012).

A first possibility consists in transforming the nonGaussian data and using the LMM. Although this approach might be appropriate, it seems more pertinent to use the raw distribution of the data (Bolker et al 2008; Wittenburg et al. 2008). GLMMs (Kachman 2007; Isik 2011; Sun 2011; Che and Xu 2012) are an extension of generalized linear models that allow the prediction of random effects. They can be used to estimate the heritabilities on the original and transformed (latent) scales and are based on the real distribution of the data.

Our results showed marked differences in variance components and heritabilities estimated using either LMM or GLMM (see Tables 3, 4, 6, and 7). This result was expected as the estimations are not based on the same scale. These observations highlight the difficulty of choosing a particular heritability expression. The interpretation and choice of these heritabilities are not trivial and are not established; more research is needed to fully exploit the potential of this kind of method (Nakagawa and Schielzeth 2010).

If we consider the impact of modeling in terms of selection efficiency, our results show that GLMM is less accurate. This lower performance affected the ranking of predicted breeding values, especially for PROD. GLMM is more adapted to nonGaussian data from a theoretical point of view, and these practical considerations show that it should be used with caution. Use of the GLMM with restricted maximum likelihood is very sensitive to non-orthogonality of the data. Nonorthogonality was pronounced in our experiments because stock plant mortality was high (36 and $25 \%$ during the first and second periods) and the mating design was not complete (Table 1). Some scientists favor the normal approximation and use of the LMM if there are numerous data points per level of a factor. However, the GLMM can still be applied by using a simpler model (eliminating a genetic effect), by simplifying the experimental design (combining factors...) or by using a more informative response variable (Gezan, personal communication).

\section{Contribution of additive and non-additive effects}

Our results showed that $\sigma^{2}{ }_{\mathrm{D}} / \sigma^{2}{ }_{\mathrm{A}}$ was close to 1 and sometimes higher than 1.5 for all the variables with the parent model (model 1). For the individual tree model (model 2), this result was amplified. Although confirmation with supplementary experiments is needed because of the small parent sample size, this result may reveal the importance of the dominance effect for propagation traits in the hybrid population. This is supported by previous findings showing the preponderance of non-additive variance for such traits, for example in Pinus taeda (Foster 1978; Anderson et al. 1999), Tsuga heterophylla (Sorensen and Campbell 1980), and Platanus occidentalis
(Cunningham 1986). The importance of dominance effects has already been stressed in the case of this $E$. urophylla $\times E$. grandis hybrid population regarding growth traits (Bouvet et al. 2009) and could be confirmed by this study on propagation ability.

\section{Heritability}

Our results indicated that PROD is more heritable than CUT. CUT is under weak genetic control (Tables 4 and 7), while PROD is under moderate to high genetic control (Tables 3 and 6). Some studies on the genetic control of propagation traits have reported similar results. Ruaud et al. (1999) reported weak and moderate heritability for rooting ability in $E$. grandis $\left(h^{2}=0.16\right.$ for cuttings derived from open pollinated families and $h^{2}=0.27$ for cuttings derived from half-diallel crossings). In E. globulus, Borralho and Wilson (1994), England and Borralho (1995), and Lemos et al. (1997) reported moderate genetic control for rooting ability, included in the range [0.36$0.41]$. In theory the lower narrow- and broad-sense heritability for CUT could be explained by a higher environmental variance due to non-optimal environmental control in the nursery, the number of cutting manipulations during the process, and a higher sensitivity of cutting to environmental changes.

\section{Genetic correlations}

The values of correlation between PROD, CUT, and growth at 25 months in the field highlighted a weak relationship between gene effects in the nursery and field. Only correlation between PROD and field growth for dominance effects was close to 0.5 . Additive correlation estimates were poor due to the very small variance components and cannot be considered as consistent. Few published results are available for comparison with our findings. Baltunis et al. (2007) reported a significant but weak genetic correlation between rooting ability and initial growth in P. taeda $\left(\rho_{\mathrm{G}}=0.29\right)$. Such a low level of correlation was expected in our experiments based on previous results showing the weak relationship between cutting growth at the nursery stage and clone performances in the field with eucalyptus hybrids in Congolese conditions (Bouvet et al 2004). This weak correlation between field growth and propagation should be confirmed, but these first results underscore the need to start improvement programs with a large genetic base population in order to select genotypes combining good growth and propagation ability.

\section{Conclusion}

This study is one of the few that address the genetics of propagation in Eucalyptus. Similar analyses have been 
conducted in E. globulus (Borralho and Wilson 1994; Lemos et al 1997), but to our knowledge very few recent studies have investigated the genetic basis for cutting success and its relation to adaptive and biomass traits. Such genetic analyses with adequate statistical models are needed to take into account the types of variables (proportion and count data). We present an alternative to the LMM that can be used according to the quality of the data and the objective (assessment of genetic parameters or BLUP). The GLMM has good potential because of its relevant mathematical properties and the ability to estimate heritability on both scales. However, the study of these different models showed that it is difficult to interpret the genetic parameters (variance, heritability,...) and the risk when the experiment is of complex design and the data are unbalanced. Additional research through simulation is needed to investigate the potential of the GLMM and the interpretation of the estimates, especially in complex genetic designs.

We observed here that cutting success is under weak genetic control and that shoot production is under moderate genetic control, and that the two traits are genetically correlated. The level of heritability, even though small, suggested that genetic gain can be achieved through breeding and clone selection. In addition, the low genetic correlations between the shoot production of stock plants and between cutting success and tree growth in the field are important to consider in breeding. In terms of multitrait selection, they show that there is a need to start breeding programs with a large genetic basis so as to be able to select clones combining good propagation properties and good growth. However, these first results need to be confirmed by additional experiments.

Acknowledgments This work was partially supported by a grant from the International Foundation of Sciences (IFS). We are grateful to the CRDPI monitoring team, to Alphonse Matsoumbou for pollination work, to David Okouo for seedling monitoring, and to Mélanie Toto, Prudence Ndoki, and Ulrich Saya for setting up and maintaining the trial and for data collection.

Data archiving statement The data will be submitted to the Dryad organization upon acceptance of the manuscript.

The data included two files in text format.

Propagation_data.txt

PERIOD (propagation period) FAMILY (family code), IND (clone code) CROSS (crossing code) FEMALE (female code) MALE (male code) PROD (number of shoots produced) CUT (number of cutting collected).

Propagation growth data.txt

PERIOD (propagation period) FAMILY (family code), IND (clone code) CROSS (crossing code) FEMALE (female code) MALE (male code) PROD (number of shoots produced) CUT (number of cutting collected).

HEIGHT25_months (height at field stage 25 months), CIR_25months (circumference at field stage 25 months).

\section{References}

Anderson HV, Frampton LJJR, Weir RJ (1999) Shoot production and rooting ability of cuttings from juvenile greenhouse loblolly pine hedges. Trans Ill State Acad Sci 92:1-14

Baltunis BS, Huber DA, White TL, Goldfarb B, Stelzer E (2007) Genetic gain from selection for rooting ability and early growth in vegetatively propagated clones of loblolly pine. Tree Genet Genomes 3: 227-238

Barbour EL, Butcher T (1995) Field testing vegetative propagation techniques of Eucalyptus globulus. In: Potts BM et al (Eds) Eucalypt plantations: improving fibre yield and quality. Proc. CRC-IUFRO Conf., Hobart 19 to 24 Feb. CRC for Temperate Hardwood Forestry, Hobart, Australia, pp 313314

Bhardwaj DR, Mishra VK (2005) Vegetative propagation of Ulmus villosa: effects of plant growth regulators, collection time, type of donor and position of shoot on adventitious root formation in stem cuttings. New For 29:105-116

Bolker BM, Brooks ME, Clark CJ, Geange SW, Poulsen JR, Stevens MHH, White JSS (2008) Generalized linear mixed models: a practical guide for ecology and evolution. Trends Ecol Evol 24(3):127135

Bonga JM (1982) Vegetative propagation in relation to juvenility, maturity, rejuvenation. In: Bonga JM, Durzan DJ (eds) Tissue culture in forestry. Martinus Nijhoff/Dr W. Junk publishers, The Hague, pp $387-412$

Borralho NMG, Wilson PJ (1994) Inheritance of initial survival and rooting ability in Eucalyptus globulus Labill. Stem cuttings. Silvae Genet 43:238-242

Bouvet JM, Vigneron P, Saya AR, Gouma R (2004) Early selection of Eucalyptus clones in retrospective nursery test using growth, morphological and dry matter criteria, in Republic of Congo. South Afr For J 200:5-17

Bouvet JM, Saya A, Vigneron P (2009) Trends in additive, dominance and environmental effects with age for growth traits in Eucalyptus hybrid populations. Euphytica 165:35-54

Browne RD, Davidson CG, Steeves TA, Dunstan DI (1997) Effect of ortet age on adventious rooting of jack pine (Pinus banksianna) long-shoot cuttings. Can J For Res 27:91-96

Browne WJ, Subramanian SV, Jones K, Goldstein H (2005) Variance partitioning in multilevel logistic models that exhibit overdispersion. J R Stat Soc Ser A Stat Soc 168:599-613

Burger DW (1987) In vitro micropropagation of E. sideroxylon. Hortic Sci 22:496-497

Carrasco JL, Jover L (2005) Concordance correlation coefficient applied to discrete data. Stat Med 24:4021-4034

Chaperon H, Quillet G (1977) Bouturage des arbres forestiers en République du Congo. Premiers résultats obtenus par la recherche. CTFT-Congo, $84 \mathrm{p}$

Che X, Xu S (2012) Generalized linear mixed models for mapping multiple quantitative trait loci. Heredity 109:41-49

Cunningham MW (1986) Genetic variation in rooting ability of American sycamore cuttings. In: Proceedings of Research and Development Conference, Sept. 1986, Atlanta. Technical Association of the pulp and paper industry, Norcross, GA, pp 1-6

Danthu P, Ramaroson N, Rambeloarisoa G (2008) Seasonal dependence of rooting success in cuttings from natural forest trees in Madagascar. Agrofor Syst 73:47-53

Davis TD (1988) Photosynthesis during adventitious rooting. In: Davis TM, Haissig BE, Sankhla N (eds) Adventitious root formation in cuttings. Dioscorides Press, Portland, pp 79-87

England N, Borralho NMG (1995) Heritability of rooting success in Eucalyptus globulus stem cuttings. In: Proc. IUFRO Conf. On Eucalypt Plantations: Improving Fibre Yield and Quality. Hobart, 
Australia, 19 to 24 Feb. CRC for Temperate Hardwood Forestry, pp 237-238

Farmer RE Jr, Freitag M, Garlick (1989) Genetic variance and "C" effects in balsam poplar rooting. Silvae Genet 38(2):62-65

Foster GS (1978) Genetic variations in rooting stem cuttings from fouryear-old loblolly pine. Weyerhauser Co., Hot Springs, AR. Tech Rep. No. 042-3204/78/97

Foster GS (1985) Genetic parameters for two eastern cottonwood populations in the lower Mississippi valley. In: Schmidtling RC, Griggs MM (eds) Proc. South. For. Tree Improv. Conf., 18:258-266

Foster GS, Bridgwater FE, McKeand SE (1981) Mass vegetative propagation of loblolly pine - a reevaluation of direction. Proc South For Tree Improv Conf 16:311-319

Foster GS, Stelzer HE, McRae JB (2000) Loblolly pine cutting morphological traits: effects on rooting and field performance. New For 19: 291-306

Gallais A (1990) Théorie de la sélection en amélioration des plantes. Collection Sciences Agronomiques, Masson, 588p

Garcia DA, Pereira IG, e Silva FF, Rosa GJM, Pires AV, Leandro RA (2012) Generalized linear mixed models for the genetic evaluation of binary reproductive traits: a simulation study. Rev Bras Zootec 41(1):52-57

Gilmour AR, Thompson R, Cullis BR (1995) Average information REML, an efficient algorithm for variance parameter estimation in linear mixed models. Biometrics 51:1440-1450

Gilmour AR, Gogel BJ, Cullis BR, Thompson R (2006) ASREML user guide, release 2.0. VSN International, Hemel Hempstead

Goldfarb B, Surles SE, Thetford M, Blazich FA (1998) Effects of root morphology on nursery and first-year field growth of rooted cuttings of loblolly pine. South J Appl For 22(4):231-234

Greenwood MS, Hutchison KW (1993) Maturation as a developmental process. In: Ahuja MR, Libby WJ (eds) Clonal forestry I-genetics and biotechnology, vol 1. Springer, Berlin, pp 14-33

Hackett WP (1985) Juvenility, maturation and rejuvenation in woody plants. Hortic Rev 7:109-155

Hackett WP (1988) Donor plant maturation and adventitious root formation. In: Davis TM, Haissig BE, Sankhla N (eds) Adventitious root formation in cuttings. Dioscorides Press, Portland, pp 11-28

Hamann A (1995) Effects of hedging on maturation in loblolly pine: rooting capacity and root formation, MSc thesis, State University of New York

Hossain MA, Islam MA, Hossain MM (2004) Rooting ability of cuttings of Swietenia macrophylla King and Chukrasia velutina Wight et Arn as influenced by exogenous hormone. Int J Agric Biol 6(3):560-564

Isik F (2011) Generalized linear mixed models - an introduction for tree breeders and pathologists. Quantitative Forest Geneticist, Cooperative Tree Improvement Program, North Carolina State University. Statistic Session class notes. Fourth International Workshop on the Genetics of Host-Parasite Interactions in Forestry. July 31-August 5, 2011. Eugene, Oregon, USA, 47p

Kachman SD (2007) An introduction to generalized linear mixed models. Armidale Animal Breeding Summer, Department of Statistics, University of Nebraska, 161p

Kovacevic B, Kraljevic-Balalic M, Zoric M (2004) Analysis of stability and adaptability of black poplar genotypes for cuttings' survival. XXXIV annual meeting of ESNA, Novi Sad. Proceedings, pp 318321

Kovacevic B, Guzina V, Ivaniševic P, Roncevic S, Andrašev S, Pekec S (2005) Variability of cuttings' rooting characters and their relationship with cuttings' survival rate for poplars of section Aigeiros. Contemp Agric 54(1-2):130-138

Kovacevic B, Guzina V, Kraljevic-Balalic M, Ivanivić M, Nikolic-Dorić (2008) Evaluation of early rooting traits of eastern cottonwood that are important for selection tests. Silvae Genet 57(1):13-21

Lemos L, Carvalho A, Araujo JA, Borralho NMG (1997) Importance of additive genetic and specific combining ability effects for rooting ability of stem cuttings in Eucalyptus globules. Silvae Genet 46(5): 307-308

MacRae S, Cotterill PP (1997) Macropropagation and micropropagation of Eucalyptus globulus: means of capturing genetic gain. In: Proc. IUFRO Conf. on Silviculture and Improvement of Eucalypts. Salvador, Brazil, 24 to 27 August, EMBRAPA, pp 102-110

Mankessi F, Saya A, Baptiste C, Nourissier S, Monteuuis O (2009) In vitro rooting of genetically related Eucalyptus urophylla $\times$ Eucalyptus grandis clones in relation to the time spent in culture. Trees 23:931-940

Mankessi F, Saya A, Toto M, Monteuuis O (2010) Propagation of Eucalyptus urophylla $\times$ Eucalyptus grandis clones by rooted cuttings: Influence of genotype and cutting type on rooting ability. Propag Ornamental Plants 10:42-49

Mankessi F, Saya A, Toto M, Monteuuis O (2011) Cloning field growing Eucalyptus urophylla $\times$ Eucalyptus grandis by rooted cuttings: age, within-shoot position and season effects. Propag Ornamental Plants 11(1):3-9

Marino TM (1982) Propagation of southern pines by cuttings. Comb Proc Int Plant Propag Soc 31:518-524

Martin B, Quillet G (1974) Bouturage des arbres forestiers au Congo: résultats des essais effectués à Pointe-Noire de 1969 à 1973. Bois et Forêts des Tropiques 154:41-59

Mc Cullah P, Nelder JA (1989) Generalized linear models, 2nd edn. Chapman \& Hall, London, p 511p

Monteuuis O, Vallauri D, Poupard C, Chauviere M (1995) Rooting Acacia mangium cuttings of different physiological age with reference to leaf morphology as a phase change marker. Silvae Genet 44 : $150-154$

Mrode RA, Thompson R (2005) Linear models for the prediction of animal breeding values, 2nd edn. CABI Publishing, Cambridge, $344 p$

Nakagawa S, Schielzeth H (2010) Repeatability for Gaussian and nonGaussian data: a practical guide for biologists. Biol Rev 85:938-956

Paul AD, Foster GS, Lester DT (1993) Field performance, C effects, and their relationship to initial rooting ability for western hemlock clones. Can J For Res 5:47-57

Piepho HP, Möhring J, Melchinger AE, Büchse A (2008) BLUP for phenotypic selection in plant breeding and variety testing. Euphytica 161:209-228

Pierik RLM (1990) Rejuvenation and micropropagation. In: Nikkamp HJJ, Van der Plas LHW, Van Aartrijk J (eds) Progress in plant cellular and molecular biology. Proceedings of the VIIth international congress on plant tissue and cell culture. Kluwer, Amsterdam, pp $91-101$

Poupard C, Chauvière M, Monteuuis O (1994) Rooting Acacia mangium cuttings: effects of age, within-shoot position and auxin treatment. Silvae Genet 43(4):226-231

Radosta P (1989) The influence of endogenous and exogenous factors on the process of rhizogensis. PhD Thesis, Forestry Research Institute, Prague

Radosta P, Pãques LE, Verger M (1994) Estimation of genetic and nongenetic parameters for rooting traits in hybrid Larch. Silvae Genet 43(2-3):108-114

Rauter RM (1983) Recent advances in vegetative propagation including biological and economic considerations and future potential. Proceedings of the IUFRO joint meeting of working parties on Genetics about breeding strategie including multiclonal varieties, Escherode, Germany, 9/1982:33-57

Ruaud JN, Lawrence N, Pepper S, Potts BM, Borralho NMG (1999) Genetic variation of in vitro rooting ability with time in Eucalyptys globulus. Silvae Genet 48(1):4-7

Saya RA, Mankessi F, Toto M, Marien JN, Monteuuis O (2008) Advances in mass clonal propagation of Eucalyptus urophylla $\times E$. grandis in Congo. Bois et Forêts des Tropiques 297:15-25 
Shepherd M, Mellick R, Toon P, Dale G, Dieters M (2005) Genetic control of adventitious rooting on stem cuttings in two Pinus elliottii $\times$ P. caribaea hybrid families. Ann For Sci 62:403-412

Sorensen FC, Campbell RK (1980) Genetic variation in root ability of cuttings from one-year-old western hemlock seedlings. USDA For. Serv. Res. Note PNW-352

Sun L (2011) Comparison of different estimation methods for linear mixed models and generalized linear mixed models. D-level Essay in Statistics, Dalarna University, Sweden, 30p

Teklehaimanot Z, Mwang'Ingo PL, Mugasha AG, Ruff OCK (2004) Influence of the origin of stem cutting, season of collection and auxin application on the vegetative propagation of African Sandalwood (Osyris lanceolata) in Tanzania. South Afr For J 201: $13-24$
Tibbits WN, White TL, Hodge GR, Kelsey R, Joyce KR (1997) Genetic control of rooting ability of stem cuttings in Eucalyptus nitens. Aust J Bot 45(1):203-210

Wareing PF (1987) Phase change and vegetative propagation. In: Abbott AJ, Atkin RK (eds) Improving vegetatively propagated crops. Academic, London, pp 263-270

Wittenburg D, Guiard V, Teuscher F, Reinsch N (2008) Comparison of statistical models to analyse the genetic effect on within-litter variance in pigs. Animal 2(11):1559-1568

Zobel BJ (1993) Clonal forestry in the Eucalyptus. In: Ahuja MR, Libby WJ (eds) Clonal forestry II, conservation and application. Springer, Berlin, pp 140-148

Zsuffa L (1968) Vegetative propagation of cotton-wood by rooting cuttings. Proc. Symposium of Eastern Cotton-wood and Related Species. Louisiana State University, pp 93-108 